\title{
Movements and site fidelity of the bonefish Albula vulpes in the northern Florida Keys determined by acoustic telemetry
}

\author{
Robert Humston $^{1,2, *}$, Jerald S. Ault ${ }^{1}$, Michael F. Larkin ${ }^{1}$, Jiangang Luo ${ }^{1}$ \\ ${ }^{1}$ Division of Marine Biology and Fisheries, University of Miami Rosenstiel School of Marine and Atmospheric Science, \\ 4600 Rickenbacker Causeway, Miami, Florida 33149, USA \\ ${ }^{2}$ Present address: Department of Biology, Virginia Military Institute, Lexington, Virginia 24450, USA
}

\begin{abstract}
We used an acoustic telemetry system to test the hypothesis that the bonefish Albula vulpes exhibits site fidelity in selection of foraging areas in the northern Florida Keys. Stationary hydrophone receivers with data-logging units were deployed surrounding a discrete bonefish foraging area. Individuals were captured, fitted with acoustic transmitters, and then released within the study area. The reception ranges of receiver stations within the array were evaluated by moving a transmitter within the array. These data were used to assess spatial coverage of monitoring and decipher fine-scale movement patterns from recorded presence-absence data: $64 \%$ of tagged fish were detected by receivers for multiple days following release. Tagged fish frequented the experimental area for periods ranging from 3 to $61 \mathrm{~d}$. Only 2 individuals, tracked for 48 and $61 \mathrm{~d}$, demonstrated site fidelity characterized by daily movements into the study area. Our observations contradict earlier studies that concluded that bonefish range widely throughout available habitats, and suggest that bonefish utilize shallow habitats most, although deep channels may provide refuge from the rapid temperature changes that occur on the shallow flats.
\end{abstract}

KEY WORDS: Bonefish $\cdot$ Acoustic telemetry $\cdot$ Site fidelity $\cdot$ Movements $\cdot$ Florida Keys

\section{INTRODUCTION}

Bonefish Albula spp. are Elopiforme species that inhabit tropical and subtropical coastal marine environments from nearshore shallows to offshore reefs. Recent observations and genetic studies have suggested that 2 species (Albula vulpes and one undescribed Albula sp.) inhabit Florida coastal marine waters (Crabtree et al. 1996, Colborn et al. 2001). However, A. vulpes, a species that attains relatively large size is the dominant, if not exclusive, species encountered by anglers fishing Florida's inshore 'flats' habitats. A pervasive conservation ethic among bonefish anglers means that most bonefish captured in the targeted sports fishery are released alive. The unique 'catch-and-release' aspect of the south Florida bonefish fishery has engendered a complacent attitude among fishery managers concerning the status of the resource, and has dissuaded formal stock assessments critical for quantifying the current condition and sustainability of the fishery. Despite their history as popular and economically important sport fishes, no comprehensive quantitative stock assessment of any bonefish population has ever been conducted.

Bonefish population biology is therefore still poorly understood. Perhaps the most significant knowledge gaps are in the area of spatial dynamics including lifestage-specific habitat requirements, stock mortality rates, reproductive ecology, maximum sizes/ages, larval dispersion and adult movement patterns. Each of these issues figures prominently in fisheries management. Bruger (1974) and Colton \& Alevizon (1983) described unsuccessful attempts at tagging Albula vulpes in Florida and the Bahamas, respectively, using con- 
ventional external marking techniques. Both studies cited a surprising lack of recaptured fish bearing tags. Humston (2001) and Ault et al. (2002) described a relatively large-scale bonefish (Albula spp.) anchortagging study ongoing in southern Florida (see www.bonefishresearch.com). This research was the first successful mark-recapture study described for bonefishes with over 2000 individuals tagged and an average recovery rate of $2.5 \%$.

Characterizing fish movement and habitat-utilization patterns can augment understanding of the spatial dynamics of fisheries and guide conservation strategies. Describing the spatial behavior of fishes with respect to the habitat or other physical characteristics of the ecosystem can help predict stock responses to changes in their environment (Cushing 1981, Ault et al. 2003). Designation of spatial refuge has assumed increasing relevance as a management action for sustaining global fisheries (Pauly et al. 2002, Lubchenco et al. 2003). Closures can be effective for managing and protecting inshore fisheries, particularly those in habitats vulnerable to shoreline development and anthropogenic degradation (Johnson et al. 1999, Roberts et al. 2001). Characterizing movement patterns - particularly home-range size and site fidelity (remaining faithful to breeding or foraging sites; see Schmidt 2004 for discussion) - is essential in reserve design and assessment (DeMartini 1993, Zeller \& Russ 1998, Cole et al. 2000, Roberts et al. 2001, Botsford et al. 2003, Gaines et al. 2003, Lowe et al. 2003, Palumbi et al. 2003, Meester et al. 2004, Weatherbee et al. 2004).

Acoustic telemetry can be employed to monitor the movement patterns of fishes at relatively high spatial and temporal resolutions (O'Dor et al. 1998, Zeller, 1999, Lucas \& Baras 2000). Studies on bonefishes (Colton \& Alevizon 1983) and a suite of other inshore, reef, coastal and pelagic marine species have provided specific information on movement patterns and habitat utilization useful to fishery management decision making (e.g. Tulevech \& Recksiek 1994, Cote et al. 1998, Zeller \& Russ 1998, Cole et al. 2000, Freon \& Dagorn 2000, Meyer et al. 2000, Arendt et al. 2001, Brill \& Lutcavage 2001, Eristhee \& Oxenford 2001, Bertrand et al. 2002, Brill et al. 2002, Robichaud \& Rose 2002, 2003, Bach et al. 2003). Here we describe the design and deployment of a hydrophone array used to test the hypothesis that the bonefish Albula vulpes exhibits site fidelity in its selection of foraging areas (i.e. shallow-water flats). We report observed patterns of appearance of telemetered fish within the monitoring station array, draw inferences concerning general patterns of movement, site fidelity and habitat use, and discuss their importance for managing this economically-important sport fishery in Florida.

\section{MATERIALS AND METHODS}

Study area. We implemented an automated acoustic telemetry (AT) system to continuously monitor movements of the bonefish Albula vulpes throughout a system of channels and barrier islands surrounding a shallow, protected 'flats habitat' situated in the barrier islands between south Biscayne Bay, Florida, and the adjacent Atlantic Ocean (Fig. 1). This allowed us to continuously monitor a relatively remote area of the coastal ocean for the presence of acoustically-tagged bonefish (O'Dor et al. 1998, Lucas \& Baras 2000; Thorstad et al. 2000, Lokkeborg et al. 2002).

We chose our study site based on the reception range of the receiving stations. Hurricane Flat is well protected by a number of small mangrove islands, and is separated from neighboring flats by relatively deep channels (Fig. 1). Wind-wave action and the associated background noise is therefore limited, as is the number of access corridors. Corridors to the flat provide a variety of habitat types from which the bonefish could enter or leave the area.

Placement of 8 hydrophone receivers was designed to maximize the probability of tag detection whenever bonefish accessed or entered the flat. We identified 3 potential access points to the flat: Jones Lagoon and Hurricane Creek corridor, Bonefish Highway, and Snake Creek (Fig. 1). Jones Lagoon is a 1 to $2 \mathrm{~m}$ lagoon at the interface between Hurricane Flat and the relatively deep channel $(>3 \mathrm{~m}$ ) which connects the flat with Caesar Creek to the east. Bonefish Highway is a shallow $(\leq 1.3 \mathrm{~m})$ corridor in the NE corner of the flat, connecting it to Caesar Creek to the $\mathrm{NE}$; receivers were placed on the east (BHE) and west (BHW) sides of Bonefish Highway because there is a very shallow bank $(<0.5)$ in the middle. Snake Creek is a deep $(2.5 \mathrm{~m}$ or more) channel, which borders the longest open boundary of the flat that separates it from a neighboring exposed flat to the west. We deployed 4 receivers in Snake Creek at locations marking likely exodus routes for bonefish from the flat. These were denoted (from south to north): Snake Creek (SC), Rubicon South (RS), Rubicon North (RN), and Reid Key (RK).

Equipment and testing. VEMCO Model VR-2 hydrophone and data-logging stations were used to monitor bonefish movements. Upon reception of a signal the data-logger recorded the time and identified the tag number by its unique coded transmission pattern. Data were periodically retrieved onto a portable computer using VEMCO's system hardware and software interface. We employed VEMCO Model V-16 coded acoustic transmitting pinger tags operating on $69 \mathrm{kHz}$ frequency with $158 \mathrm{~dB}(1 \mu \mathrm{Pa}$ at $1 \mathrm{~m})$ power output. Tags were preprogramed with 10 to $35 \mathrm{~s}$ random delays between individual transmissions that in- 


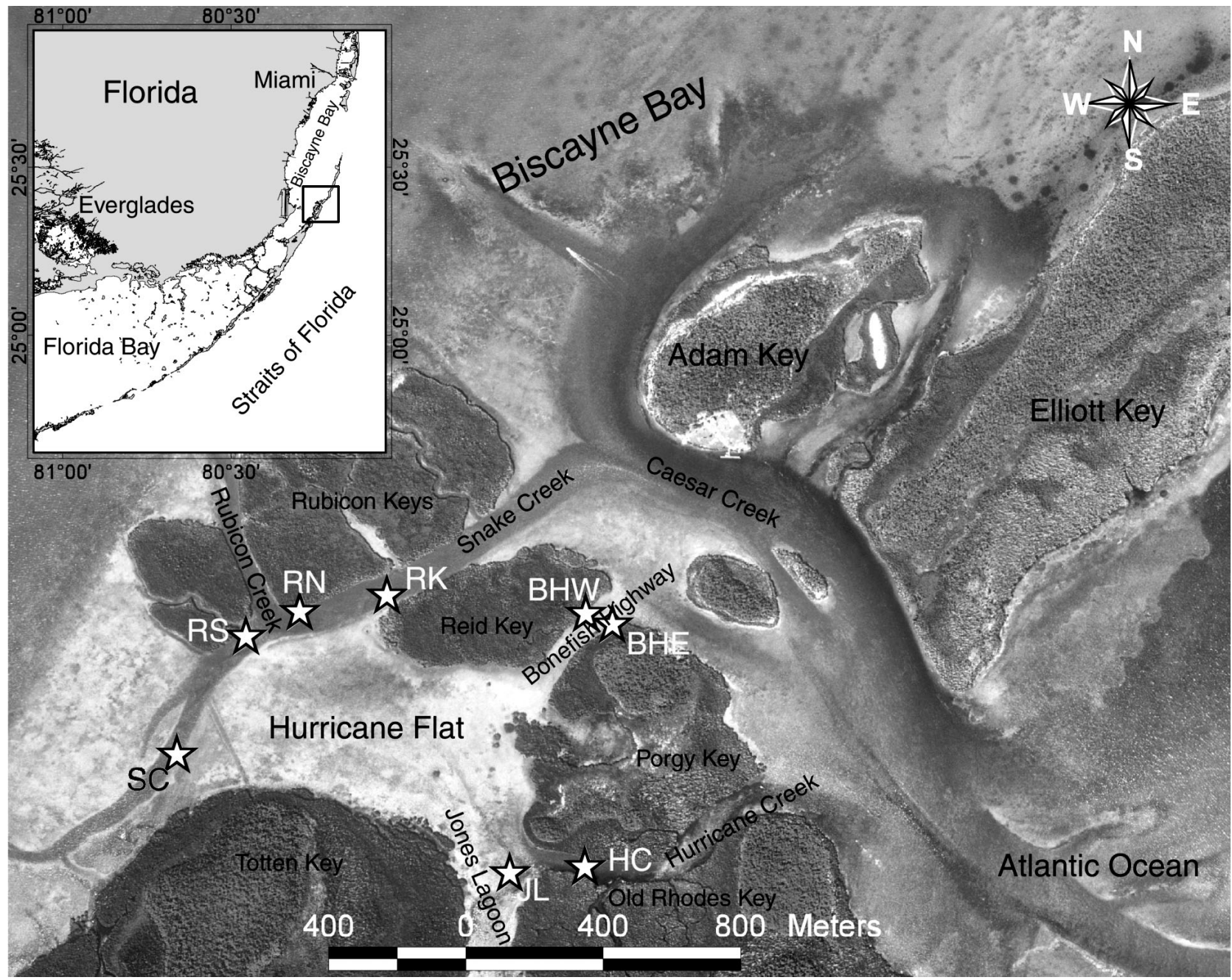

Fig. 1. Study area showing details of shallow flats, channels, mangrove islands, and other surrounding features. Individual hydrophone receiver locations are indicated by stars; BHE, BHW: east and west of Bonefish Highway, respectively; HC: Hurricane Creek; JL: Jones Lagoon; RK: Reid Key; RN, RS: Rubicon north and south, respectively; SC: Snake Creek

creased battery life and allowed the tags to transmit information for a minimum period of at least $38 \mathrm{~d}$ postactivation. The relatively short delay time maximized the probability of tag transmission when tagged fish were in range of a receiver (Lokkeberg et al. 2002). The signal output level was selected to maximize transmission power and receiver detection range.

To assess detection ranges, we towed an activated tag in predetermined patterns around the receiver stations during low, mid, and high tidal stages. The tag was deployed from a boat and weights were used to keep the transmitter at a height of $6 \mathrm{~cm}$ from the substrate. Location of the boat was recorded at $1 \mathrm{~s}$ intervals with a laptop computer connected to a WAASenabled global positioning system (GPS). To match the time of detection of the acoustic tag at each receiver with the GPS locations, all receivers were initially syn- chronized within $1 \mathrm{~s}$ using the official US atomic clock time (see www.time.gov). To assess potential variance or 'time drift' of individual receiver clocks, we used a VEMCO VR28 tracking system to record transmission time of 10-ping sequences emitted immediately adjacent to each receiver. This provided a known 'time stamp' for each receiver and allowed correction for time drift during data analysis.

Acoustic tags were $58 \mathrm{~mm}$ long and $16 \mathrm{~mm}$ in diameter and were implanted into the peritoneal cavity of bonefish using standard field surgical procedures (Hart \& Summerfelt 1975, Colton \& Alevizon 1983, Lucas \& Baras 2000). Bonefish were angled using the heaviest hook-and-line equipment feasible to minimize capture time and stress. Following capture, fish were placed ventral-side up in a soft-mesh cradle suspended in an insulated cooler containing fresh seawater and a recir- 


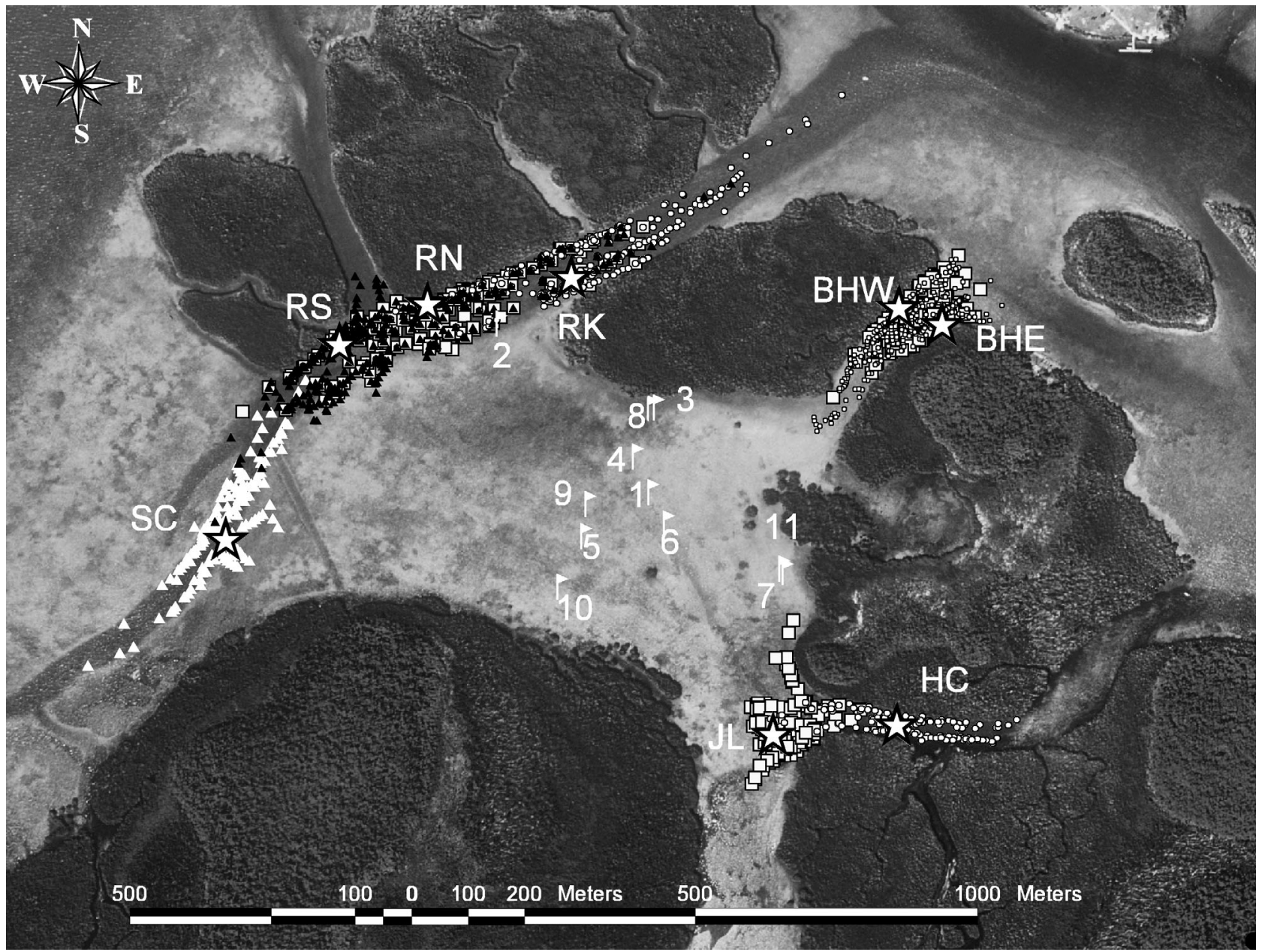

Fig. 2. Receiver detection ranges. Small symbols indicate locations of test transmissions recorded: ( $\square$ ) RN, BHE, or JL receptions; (O) RK, BHW, or HC receptions; ( $\Delta$ ) SC receptions; ( $\Delta$ ) RS receptions. Numbered white flags denote release locations of individual tagged bonefish. Abbreviations as in Fig. 1

culating pump. Pump outflow was positioned to allow water flow through the mouth and over the gills of fish during surgery. No anesthetics were employed during the process of tag implantation. Tags were inserted through an approximate $2 \mathrm{~cm}$ incision along the ventral midline between the pelvic girdle and the anal vent. Incisions were closed using Softsilk ${ }^{\circledR}$ suture material and cyanoacrylate adhesive. Fish were allowed to recover in the onboard holding tank immediately following surgery, and then transferred to a $3 \mathrm{~m}$ diameter pen temporarily erected on the flat. This pen allowed the fish to recover unthreatened by predators until they were deemed fit for release. All fish were released within $2 \mathrm{~h}$ post-surgery to minimize potential deleterious effects from extended confinement (Lucas \& Baras 2000). All fish were further identified with conventional T-bar anchor tags (Floy Tag)

Between November 8, 2001 and July 31, 2002, 11 bonefish were tagged and released with acoustic transmitters in the study area (Table 1). We suspended tagging operations during the winter months (January through March) because of peak bonefish spawning activity (Crabtree et al. 1997). Our test trials indicated that adult bonefish with fully developed gonads (ovaries or testes) were less likely to survive the surgical implant procedure; in addition, spawning-related movements could bias conclusions on site fidelity and habitat utilization.

Movement and site-fidelity patterns were compared with data on (1) tidal stage and height, (2) average and maximum daily air temperature (a proxy for shallow-water warming potential), (3) daylight versus night hours, and (4) full moon versus new moon periods. Movement was also analyzed with respect to habitat characteristics associated with individual receiver positions. Receivers were rank-ordered according to water depth to examine individual depth preferences. 


\section{RESULTS}

\section{Calibration of receiver detection ranges}

Reception ranges for all stationary hydrophones during low, mid and high tidal phases are shown in Fig. 2. Maximum detection distances ranged from $230 \mathrm{~m}$ ( $\mathrm{HC}$, $\mathrm{JL}$ and $\mathrm{BHE}$ ) to about $750 \mathrm{~m}$ (RS). At JL and HC, simultaneous detection of pings by both receivers was limited to the western entrance of the Hurricane Creek. At low tide in Bonefish Highway, BHE and BHW receivers were shielded by a shallow bank in the middle of the channel; this resulted in a very small area of overlap in the middle of the creek. The $\mathrm{BHW}$ receiver was able to detect transmissions to the NE outer edge of the central flat, while the BHE receiver only detected transmissions along a narrow path between a small mangrove island and Porgy Key. During rising mid to high tides, both BHW and BHE receivers detected transmissions from across the channel; thus, the area of overlap increased to the entire cross-section of the channel within $100 \mathrm{~m}$ of either receiver. At Snake Creek, detections were limited to those transmissions originating from within the deep channel. RK was the only receiving station capable of detecting transmissions at the extreme NE end of Snake Creek, while receiver SC monitored the creek along the SW edge of the flat.

Based on individual and overlapping spatial patterns of reception, 4 temporal reception patterns were interpreted as 'exit signals'. Exit from the study area via Hurricane Creek was revealed by a series of detections first recorded by the JL receiver, then by both JL and HC receivers simultaneously, then finally by detections only at the $\mathrm{HC}$ receiver followed by an extended absence of receptions at any receiver, since there is no exit route through Jones Lagoon. Exit via the Bonefish Highway was characterized by detections first recorded by BHW, then simultaneously by BHW and BHE, and finally a few detections by BHE alone before an extended absence. Exit through the north end of Snake Creek was characterized by simultaneous detections on a combination of RS, RN and RK receivers, followed by detection by RK alone and subsequent absence. Exit through the SW end of Snake Creek was characterized by simultaneous detections of RS and SC, followed by SC alone. The reverse of these data sequences indicated return to the study area following excursions elsewhere. There was 1 exception: fish leaving the area via the shallow $(<0.5 \mathrm{~m})$ corridor between Snake Creek and Totten Key apparently could not be detected by any of the receivers in our array.

\section{Tracking of acoustically tagged bonefish}

Individual data on fish sizes, dates of release and dates of last recorded transmission are provided in Table 1 . The hydrophone receiver array recorded a total of 8210 transmissions from tagged fish over 120 unique (non-consecutive) days from 7 of 11 tags following deployment. Of these 7 tags, 5 were detected intermittently every day for a period of 3 to $4 \mathrm{~d}$. The remaining 2 tags were detected intermittently every day for periods of 40 and $61 \mathrm{~d}$, respectively (Table 1). Data on transmissions received at each receiving station from individual bonefish are summarized in Table 2. The majority of detections were recorded by BHW and JL receivers. On July 28, 2002, the RN receiver was moved to the $\mathrm{SC}$ location, as the original $\mathrm{SC}$ receiver had been stolen. This reduced the total number of receivers available to 7 , but did not compromise our ability to detect egress through the NW quadrant of the study area (Fig. 2).

Bonefish No. 1. Bonefish No. 1 was detected by 4 of the 8 hydrophones 2881 times between November 8 and December 18, 2001. Detection sequences indicated that the bonefish remained within the study area. There were some extended periods (up to $14 \mathrm{~h}$ ) during which no transmissions were detected; however the preceding detection patterns were inconsistent with those identified as exit signals.

Bonefish No. 3. Bonefish No. 3 was detected by 5 of 8 hydrophones 208 times between April 12 and 16, 2002, but it left and re-entered the study area at least 3 times. Less than 50 min 
Table 2. Albula vulpes. Total number of transmissions recorded at each of 8 remote hydrophone receivers from bonefish tagged with acoustic transmitters. nf: receiver not functioning. Receiver abbreviations as in Fig. 1; depth rank is shown from deepest (1) to shallowest (8)

\begin{tabular}{|c|c|c|c|c|c|c|c|c|c|}
\hline \multirow{2}{*}{$\begin{array}{l}\text { Bonefish } \\
\text { No. }\end{array}$} & \multicolumn{8}{|c|}{ Hydrophone receiver, absolute depth/depth rank } & \multirow{2}{*}{ Total } \\
\hline & $\begin{array}{c}\mathrm{RN} \\
4.6 \mathrm{~m} / 1\end{array}$ & $\begin{array}{c}\mathrm{RS} \\
4.3 \mathrm{~m} / 2\end{array}$ & $\begin{array}{c}\mathrm{RK} \\
4.2 \mathrm{~m} / 3\end{array}$ & $\begin{array}{c}\mathrm{HC} \\
3.7 \mathrm{~m} / 4\end{array}$ & $\begin{array}{c}\mathrm{SC} \\
3.5 \mathrm{~m} / 5\end{array}$ & $\begin{array}{c}\mathrm{JL} \\
1.8 \mathrm{~m} / 6\end{array}$ & $\begin{array}{c}\text { BHW } \\
1.5 \mathrm{~m} / 7\end{array}$ & $\begin{array}{c}\mathrm{BHE} \\
1.5 \mathrm{~m} / 8\end{array}$ & \\
\hline 1 & 0 & 0 & 0 & 72 & 0 & 1146 & 1568 & 95 & 2881 \\
\hline 3 & 0 & 0 & 18 & 36 & 0 & 11 & 96 & 41 & 202 \\
\hline 4 & 0 & 0 & 0 & $640^{\mathrm{a}}$ & 0 & $103158^{a}$ & 0 & 0 & $103798^{a}$ \\
\hline 5 & 440 & 538 & 11 & 153 & 0 & 940 & 978 & 188 & 3248 \\
\hline 6 & 21 & 16 & 16 & 1 & 0 & 13 & 372 & 195 & 634 \\
\hline 7 & 0 & 0 & 1 & 15 & 0 & 8 & 17 & 1 & 42 \\
\hline 8 & 1 & 1 & 18 & 15 & 0 & 55 & 354 & 117 & 561 \\
\hline 10 & $\mathrm{nf}$ & 34 & 26 & 15 & 2 & 33 & 418 & 114 & 642 \\
\hline Total & 462 & 589 & 90 & 307 & 2 & 2206 & 3803 & 751 & 8210 \\
\hline
\end{tabular}

after release at the western boundary of the flat, the fish left the area via the Bonefish Highway and then re-entered via the north end of Snake Creek $20 \mathrm{~min}$ later. Near low tide at 11:00 h, the fish left the flat via the Bonefish Highway and returned approximately $25 \mathrm{~h}$ later through Hurricane Creek. The fish spent about 30 min near the Hurricane Creek's shallow western station before leaving the area via the opposite end of the channel. On April 14 and 16, the fish returned briefly to the north end of Snake Creek, but did not appear to re-enter the shallow flat.

Bonefish No. 4. Bonefish No. 4 was detected exclusively at the JL and $\mathrm{HC}$ receivers, beginning shortly after release. The frequency and consistent location of receptions would suggest either a highly localized movement pattern, or no movement at all (i.e. a dead fish or shed tag).

Bonefish No. 5. Bonefish No. 5 was detected each day between May 22 and July 21, 2002, by 7 of 8 receivers, and no signal reception patterns were recorded that would indicate this that fish left the study area. Rather, it exclusively used the interior of the flat, channel areas within the receiver array, and the adjacent Jones Lagoon area.

Bonefish No. 6. Bonefish No. 6 was detected each day between May 22 and 25, 2002, at 7 of 8 receivers. The fish left through the Bonefish Highway at 15:37 h on May 23 and returned via Snake Creek 7.5 h later. On May 25, the fish spent $1.5 \mathrm{~h}$ near the BHE and BHW receivers before exiting the array and not returning.

Bonefish No. 7. Bonefish No. 7 was detected by 5 of 8 receivers every day between May 27 and 30, 2002. After being released near the eastern mangrove boundary of the flat, the fish exited through Hurricane Creek. Over the first $60 \mathrm{~h}$ it was detected sporadically by $\mathrm{BHW}, \mathrm{BHE}$ and RK receivers, indicating that the fish stayed near the perimeter of the monitored area. After May 30, transmissions were received only by JL and
$\mathrm{HC}$ receivers, suggesting either highly localized or no movements (i.e. the fish died or shed the tag).

Bonefish No. 8. Bonefish No. 8 was detected by 7 of 8 receivers every day between May 31 and June 3, 2002, after which no further transmissions were recorded. On June 1 it left through the Bonefish Highway at 18:25 h and re-entered $5 \mathrm{~h}$ later via Hurricane Creek. The fish left the flat again via the Bonefish Highway 2 d later and did not return.

Bonefish No. 10. Bonefish No. 10 was detected at all 7 available receivers between July 31 and May 8, 2002 (during this period the $\mathrm{SC}$ receiver was stolen). The fish spent the first $24 \mathrm{~h}$ post-release exclusively in the area around $\mathrm{BHW}$ and $\mathrm{BHE}$ receivers. It left the flat area several times, generally returning within $30 \mathrm{~min}$. In one instance, the fish remained outside the study area for $5 \mathrm{~h}$. On May 8 the fish left via Bonefish Highway and did not return.

\section{Comparisons of movement patterns with physical data}

Only Bonefish Nos. 1 and 5 provided enough data to examine patterns of movement in relation to changes in physical variables of the local environment. Bonefish No. 1 primarily utilized the shallow sections of the study area; the vast majority of transmissions were detected by the 3 shallowest receivers (BHW, BHE and $\mathrm{JL})$, with no reception recorded at any of the receivers stationed in the deep channel along the western boundary. Bonefish No. 5 showed more variation in depth preference, and analyses suggest that this pattern may correlate with behavioral thermoregulation. During the period June 3 to 9, 2002, the daily air temperature rose abruptly (Fig. 3). In the same period, Bonefish No. 5 displayed a marked shift in habitat preference, from visiting predominantly the 3 shallowest receivers to spending more time around the deep- 

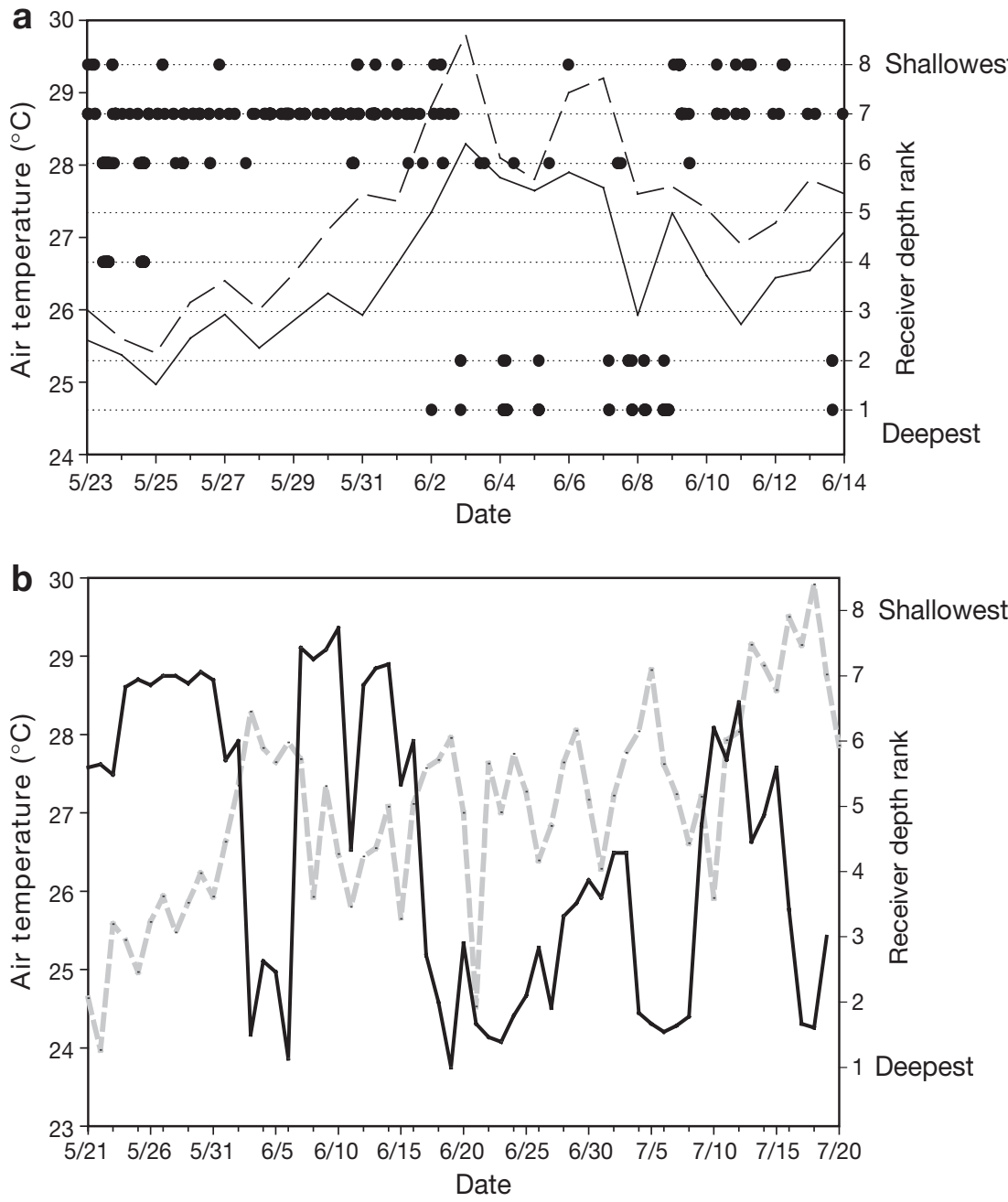

Fig. 3. Albula vulpes. Time series of recorded transmissions from Bonefish No. 5. Hydrophone receivers rank-ordered from deepest (1) to shallowest (8). (a) Average daily air temperature (continuous line) and maximum daily temperature (dashed line) against receptions $(\bullet)$ by receivers for period May 23 to June 14, 2002. (b) Average daily air temperature (dashed line) against daily mean receiver depth rank for the entire tag data series. Dates are given as mo/d

Range-testing also allowed us to resolve individual movements of Bonefish No. 1 and 5 at relatively fine spatiotemporal scales. Approximately $20 \mathrm{~min}$ following release at 11:50:00 h on May 22, 2002. Bonefish No. 5 was detected by RK (Fig. 5), and then by RN and RS receivers with some simultaneous detections. This indicates that the fish was at the NW edge of the flat and moved W by SW within the channel. About 50 min later, signals detected by $\mathrm{HC}$ and JL receivers indicated that it had moved across the flat to the SE edge (Fig. 5b,c), where it remained for $3 \mathrm{~h}$ (indicated by intermittent signals received by JL receiver; Fig. 5a). Gaps in signal reception occurred when Bonefish No. 5 moved into areas west or south of the JL receiver detection range (reception patterns not consistent with exit through Hurricane Channel). At approximately 14:51:00 h it left this area and crossed quickly (within $4 \mathrm{~min}$ ) to the NE corner of the flat, where it was detected by the BHW receiver (Fig. 5a). The distance between the 2 areas is about $400 \mathrm{~m}$, so average swimming speed was $1.66 \mathrm{~m}$ $\mathrm{s}^{-1}$ or 3 body-lengths $\mathrm{s}^{-1}$. Over the next 30 min, Bonefish No. 5 remained within the shallow Bonefish Highway channel, as signals were received by both BHW and BHE receivers (Fig. 5a). It then moved back toward the interior of the flat and made short incursions into the NE quadrant of the flat, where it was occasionally detected at BHW. At 16:50:31 h, the bonefish was detected once by the $\mathrm{BHW}$ receiver, then it crossed back to the SE corner of the flat, detected by the JL receiver at 17:05:23 h. Near peak high-

est receivers. The opposite shift occurred as temperatures decreased after June 9, 2002. Average receiver rank-order by depth and average daily air temperature negatively covaried (cov $=-0.593)$; however, the 2 variables displayed a non-significant negative correlation $(\mathrm{r}=-0.216, \mathrm{p}=0.09797)$. Bonefish No. 5 also displayed a pattern of restricted movement near the edge of the flat during rising tide, followed by an extended absence during the peak of the flood period and/or during the falling tide (Fig. 4). Reception patterns indicate that the fish moved to the central area of the flat during these absence periods. Similar tiderelated movements were observed in data from Bonefish No. 1, but were not consistent on the same time scale. tide, Bonefish No. 5 spent an extended period within the interior of the flat, and returned to Bonefish Highway over 6 h later (Fig. 5a).

Bonefish No. 1 showed a more restricted movement pattern. The first signal was detected by the JL receiver at 14:31:16 $\mathrm{h}$ (Fig. 6a), about $90 \mathrm{~min}$ after release in the middle of the flat on November 8, 2001 (Fig. 2). At 17:11:00 h, signals were detected simultaneously at the HC and JL receivers (Fig. 6b,c), indicating that the fish was in the west entrance of Hurricane Creek. The fish did not exit via Hurricane Creek, since the $\mathrm{HC}$ receiver did not detect a series of consecutive signals independent of JL. The fish returned to the SE corner of the flat (as indicated by intermittent signals received by the JL receiver; Fig. 6b). The fish was not 

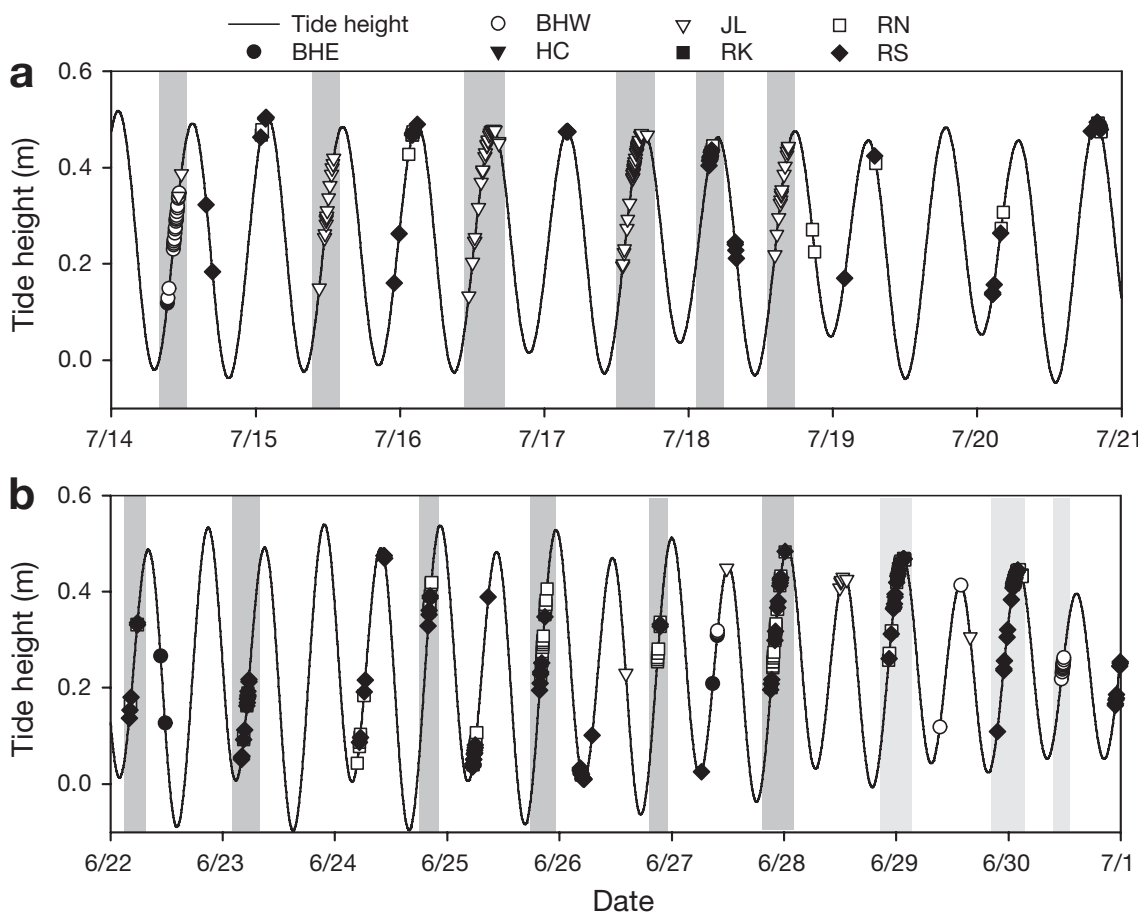

Fig. 4. Albula vulpes. Tag transmission from Bonefish No. 5 detected at individual hydrophone receivers plotted against corresponding cyclical variation in tidal height (line). Gray bars indicate periods of highly localized movement preceeding high tide. Receiver abbreviations as in Fig. 1; dates given as mo/d

detected by any other receiver until nearly $24 \mathrm{~h}$ after release, when signals were received at $\mathrm{BHE}$ and $\mathrm{BHW}$ (Fig. 6a). A lack of simultaneous receptions indicates that the fish did not exit through this channel.

\section{DISCUSSION}

Of 11 tagged fish, 7 (64\%) were detected repeatedly over time-scales ranging from days to months; 2 remained in the study area over the life span of their acoustic transmitters (40 and $61 \mathrm{~d}$ ), revealing a very high degree of site fidelity. Our results are contrary to those of Colton \& Alevizon (1983): Of 13 fish tagged with acoustic transmitters in their study, only 3 were relocated despite extensive sampling, and daily visitation did not persist after $5 \mathrm{~d}$, though 1 fish was relocated in the same area 14 times over a period of $100 \mathrm{~d}$. Based on their results (including zero recaptures in a concomitant mark-recapture study) Colton \& Alevizon (1983) concluded that site fidelity did not persist beyond 'several days' and instead that bonefish range widely within the nexus of available foraging grounds. This was not the case in our study area. Our greater detection success may be attributable to increased sampling efficiency afforded by automated telemetry technology, as opposed to a single, boat-mounted hydrophone.
Our data, however, show substantial variability between individuals, limiting any general characterizations. Most tagged fish returned only for the first 3 to $4 \mathrm{~d}$ following release. Plausible explanations for this pattern include (1) a change in movement behavior (e.g. shift in foraging area selection), or (2) these bonefish died or shed their tags a few days following release. Spatial shifts in foraging effort would be consistent with hypotheses offered by Colton \& Alevizon (1983). Mortality rates associated with this surgical implant method are low (Jepsen et al. 2002, Bridger \& Booth 2003), although reduced predator-avoidance capability due to physiological effects of surgery is possible (Adams et al. 1998, Bridger \& Booth 2003). Shedding of surgically implanted tags is unlikely on this short time-scale (see Lucas \& Baras 2000, Bridger \& Booth 2003).

In our study, 3 fish were never detected; this could be attributable to tag-failure, mortality or failure of the array to detect movement out of the study area. Range tests (Fig. 2) suggest the last possibility is not likely, unless movement occurred through the area between Snake Creek and Totten Key (Fig. 1). This location is extremely shallow and probably impassable at low tide. Also, the SC hydrophone received only 2 transmissions during the entire study period, indicating low bonefish activity in this area.

The 2 longest data sets (Bonefish Nos. 1 and 5) did not contain reception patterns indicative of exit from the monitored area, and we believe that these 2 fish did not leave the study area. It is possible that they escaped detection as they moved out of the area; however, reception patterns were consistent with movement from the interior of the flat to the monitored edges. This indicates that these bonefish would have exited and returned via the same undetectable corridor. This could only occur through the shallow area between Snake Creek and Totten Key, which we believe offered limited opportunity for passage.

No consistent movement patterns were detected that suggested either diel variation in habitat use or correlations with moon phase. A pattern that was consistent in the data was the predominance of transmissions received by BHW and JL (Table 2). These receivers were both in fairly shallow water (1 to $2 \mathrm{~m}$ ), which limited their reception range (Fig. 2). If habitat use were equitably distributed within the study area, 


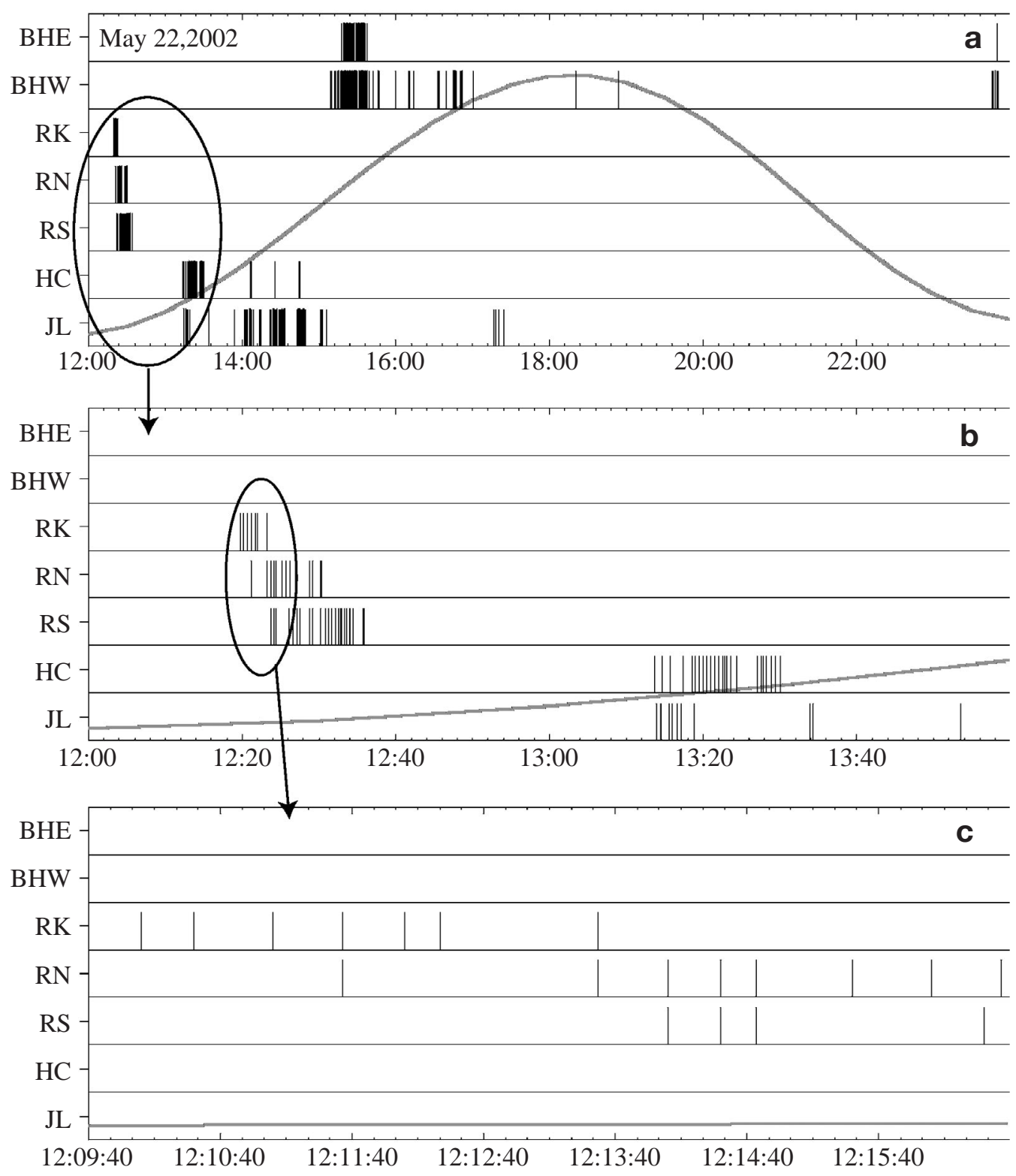

Fig. 5. Albula vulpes. Time series of recorded transmission from Bonefish No. 5 on May 22, 2002. Vertical lines: signals detected at each receiver; continuous curve: tidal phase. Receiver location is indicated on $y$-axis and time (Eastern Standard Time) on $x$-axis. (a) Fine-scale movements revealed by location of acoustic tag signals detected by individual receivers. (b) Details of time period indicated by ellipse in (a). (c) Detail of time period indicated by ellipse in (b). Receiver abbreviations as in Fig. 1

these receivers should have recorded proportionally fewer transmissions. It has been observed that bonefish use deep channels as primary routes between shallow foraging grounds, but our data do not support this. Avoidance of deep channels by bonefish may assist in predator avoidance, as the largest predators (e.g. sharks and dolphins) have limited ability to venture on to the shallow flats. We made no formal assessment of predator abundance in adjacent channels, although sharks were frequently encountered in the area; 1 hooked bonefish was attacked by a shark in Snake Creek during capture. The average size of bonefish in our study was smaller than the average size reported in recreational fishery catch data (Crabtree et al. 1996, Humston 2001, Ault et al. 2002), and depth preference may be a function of fish size and/or ontogeny. This pattern may have implications for identifying and protecting critical habitats for bonefish, as nearshore flats are frequently vulnerable to alteration or degradation by coastal shoreline development. 


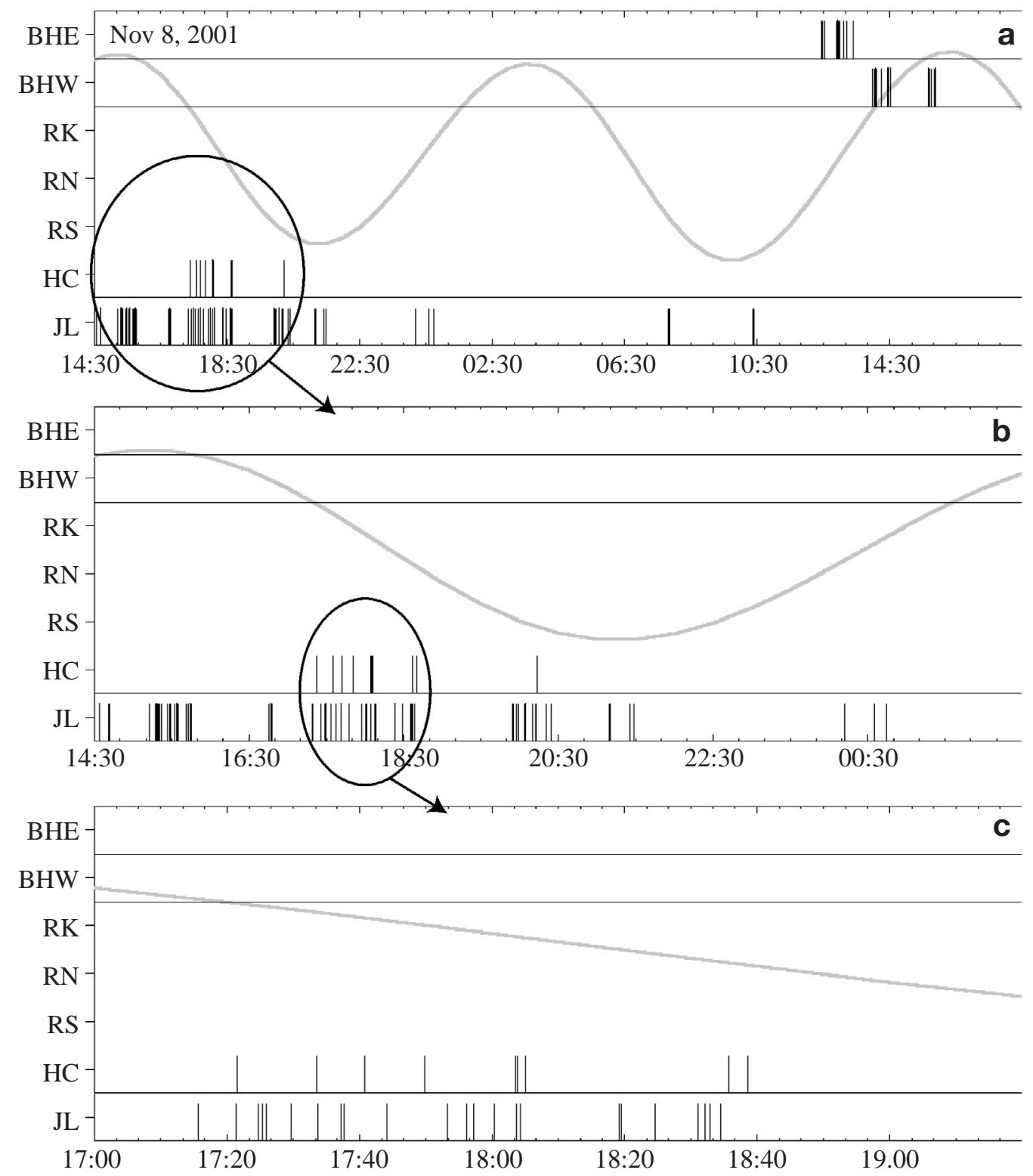

Fig. 6. Albula vulpes. Time series of recorded transmission from Bonefish No. 1 on November 8, 2001. (a) Transmissions received during first $24 \mathrm{~h}$ of reception following release. (b) Details of time period indicated by ellipse in (a). (c) Detail of time period indicated by ellipse in (b). Further details as in Fig. 5

Colton \& Alevizon (1983) showed that bonefish venture onto the flats during periods of high or rising tide and retreat into deep depressions during periods of low tides. Connections between movement patterns and tidal exchange can also be seen in our data, including recurring patterns of highly localized 'staging' (a period of low movement generally preceding a significant movement event) during rising tides (Fig. 4). Such behavior was noted in the deep channel along the western boundary (Snake Creek), in the shallow NE channel (Bonefish Highway), and at the median depth interface with Jones Lagoon to the south. Bonefish may have been responding to dynamics of tide flow at these edge/interface locations, perhaps providing unique foraging opportunities. The lack of transmissions following peak high tides probably indicates foraging excursions into the shallow interior of the flat (where automated acoustic telemetry stations could not be located). During tide cycles when no detections were recorded, it is possible that bonefish utilized deeper depressions within the interior of the flat that were not monitored. This would be consistent with the pattern observed by Colton \& Alevizon 
(1983), whereby bonefish retreated to deep recesses when falling tides precluded access to very shallow sections. Increasing receiver coverage to include such interior recessions would improve this aspect of analysis.

Bonefish display thermal preferences and are not found on shallow flats during the warmest or coldest periods of the year (Ault et al. 2002). Shallow waters are more susceptible to daily temperature fluctuations. We hypothesize that bonefish retreat to deeper areas adjacent to the flats in response to rapid temperature fluctuations in the shallows. Movement data for Bonefish No. 5 were collected during a period of transition from mild spring weather to the warm summer months. During summer months, the water temperature on the flats reached $32^{\circ} \mathrm{C}$ while the temperature at the nearby channels was around $30^{\circ} \mathrm{C}$. This may provide the incentive for bonefish to retreat to deep channels in a form of behavioral thermoregulation. The pattern in Fig. 3 qualitatively suggests that Bonefish No. 5 frequented deep areas more during peaks in daily air temperature.

We found that bonefish display site fidelity in their selection of foraging grounds over time-scales ranging from days to months and utilize shallow habitats more than deep channels. Our observations do not support the hypothesis that deep channels are used as routes between foraging areas. The avoidance of deep channels may provide protection from sharks and other large predators. However, channels may function as an important refuge from the daily variations in water temperature on the shallow flats.

Acknowledgements. We acknowledge grants to J.S.A. and R.H. from the National Fish and Wildlife foundation (grants No. 20010078000-SC and No. 20040050000-SC), to J.S.A. from the Friends of the Sanctuary and Bonefish and Tarpon Unlimited, and to R.H. from the International Light Tackle Tournament Association. We also thank the following: Captains J. Murphy and S. Venini for assistance in capturing fish; N. Farmer, P. Teare, and L.Ockelmann-LoBello for field assistance; Biscayne National Park for vessel and facilities use; and T. N. Davidson, Chairman of Bonefish and Tarpon Unlimited, for his encouragement and continued support of this research.

\section{LITERATURE CITED}

Adams NS, Rondorf DW, Evans SD, Kelly JE, Perry RW (1998) Effects of gastrically implanted radio transmitters on swimming performance and predator avoidance of juvenile chinook salmon. Can J Fish Aquat Sci 55:781-787

Arendt MD, Lucy JA, Evans DA (2001) Diel and seasonal activity patterns of adult tautog, Tautoga onitis, in lower Chesapeake Bay, inferred from ultrasonic telemetry. Environ Biol Fish 62:379-391

Ault JS, Humston R, Larkin MF, Luo J (2002) Development of a bonefish conservation program in south Florida. National Fish and Wildlife Foundation, Washington, DC
Ault JS, Luo J, Wang JD (2003) A spatial ecosystem model to assess spotted seatrout population risks from exploitations and environmental changes. In: Bortone S (ed) Biology of spotted seatrout. CRC Press, Boca Raton, FL, p 267-296

Bach P, Dagorn L, Bertrand A, Josse E, Misselis C (2003) Acoustic telemetry versus monitored longline fishing for studying the vertical distribution of pelagic fish: bigeye tuna (Thunnus obesus) in French Polynesia. Fish Res 60: 281-292

Bertrand A, Josse E, Bach P, Gros P, Dagorn L (2002) Hydrological and trophic characteristics of tuna habitat: consequences on tuna distribution and longline catchability. Can J Fish Aquat Sci 59:1002-1013

Botsford LW, Micheli F, Hastings A (2003) Principles for the design of marine reserves. Ecol Appl 13:25-31

Bridger CJ, Booth RK (2003) The effects of biotelemetry transmitter presence and attachment procedures on fish physiology and behavior. Rev Fish Sci 11:13-34

Brill RW, Lutcavage ME (2001) Understanding environmental influences on movements and depth distributions of tunas and billfishes can significantly improve population assessments. In: Sedberry GR (ed) Island in the stream: oceanography and fisheries of the Charleston Bump. American Fisheries Society, Bethesda, MD, p 179-198

Brill R, Lutcavage M, Metzger G, Bushnell P, Arendt M, Lucy J, Watson C, Foley D (2002) Horizontal and vertical movements of juvenile bluefin tuna (Thunnus thynnus), in relation to oceanographic, conditions of the western North Atlantic, determined with ultrasonic telemetry. Fish Bull US Natl Mar Fish Serv 100:155-167

Bruger GE (1974) Age, growth, food habits, and reproduction of bonefish, Albula vulpes, in south Florida waters. Florida Marine Research Publications, No. 3, Florida Department of Natural Resources, St Petersburg, FL

Colborn J, Bowen BW, Crabtree RE, Shaklee JB, Pfeiler E (2001) The evolutionary enigma of bonefishes (Albula spp.): cryptic species and ancient separations in a globally distributed shorefish. Evolution 55:807-820

Cole RG, Villouta E, Davidson RJ (2000) Direct evidence of limited dispersal of the reef fish Parapercis colias (Pinguipedidae) within a marine reserve and adjacent fished areas. Aquat Conserv 10:421-436

Colton DE, Alevizon WS (1983) Movement patterns of bonefish, Albula vulpes, in Bahamian waters. Fish Bull US Natl Mar Fish Serv 81:148-154

Cote D, Scruton DA, Niezgoda GH, McKinley RS, Rowsell DF, Lindstrom RT, Ollerhead LMN, Whitt CJ (1998) A coded acoustic telemetry system for high precision monitoring of fish location and movement: application to the study of nearshore nursery habitat of juvenile Atlantic cod (Gadus morhua). Mar Technol Soc J 32:54-62

Crabtree RE, Harnden CW, Snodgrass D, Stevens C (1996) Age, growth, and mortality of bonefish, Albula vulpes, from the waters of the Florida Keys. Fish Bull US Natl Mar Fish Serv 94:442-451

Crabtree RE, Snodgrass D, Harnden CW (1997) Maturation and reproductive seasonality in bonefish, Albula vulpes, from the waters of the Florida Keys. Fish Bull US Natl Mar Fish Serv 95:456-465

Cushing DH (1981) Fisheries biology: a study in population dynamics. University of Wisconsin Press, Madison, WI

DeMartini EE (1993) Modeling the potential of fishery reserves for managing Pacific coral-reef fishes. Fish Bull US Natl Mar Fish Serv 91:414-427

Eristhee N, Oxenford HA (2001) Home range size and use of space by Bermuda chub Kyphosus sectatrix (L.) in 2 
marine reserves in the Soufriere Marine Management Area, St Lucia, West Indies. J Fish Biol 59:129-151

Freon P, Dagorn L (2000) Review of fish associative behaviour: toward a generalisation of the meeting point hypothesis. Rev Fish Biol Fish 10:183-207

Gaines SD, Gaylord B, Largier JL (2003) Avoiding current oversights in marine reserve design. Ecol Appl 13:32-46

Hart LG, Summerfelt RC (1975) Surgical procedures for implanting ultrasonic transmitters into flathead catfish (Pylodictis olivaris). Trans Am Fish Soc 104:56-59

Humston R (2001) Development of movement models to assess the spatial dynamics of marine fish populations. $\mathrm{PhD}$ dissertation, University of Miami, Miami, FL

Jepsen N, Koed A, Thorstad EB, Baras E (2002) Surgical implantation of telemetry transmitters in fish: how much have we learned? Hydrobiologia 483:239-248

Johnson DR, Funicelli NA, Bohnsack JA (1999) Effectiveness of an existing estuarine no-take fish sanctuary within the Kennedy Space Center, Florida. North Am J Fish Manag 19:436-453

Lokkeborg S, Ferno A, Jorgensen T (2002) Effect of positionfixing interval on estimated swimming speed and movement pattern of fish tracked with a stationary positioning system. Hydrobiologia 483:259-264

Lowe CG, Topping DT, Cartamil DP, Papastamatiou YP (2003) Movement patterns, home range, and habitatutilization of adult kelp bass Paralabrax clathratus in a temperate no-take marine reserve. Mar Ecol Prog Ser 256:205-216

Lubchenco J, Palumbi SR, Gaines SD, Andelman S (2003) Plugging a hole in the ocean: the emerging science of marine reserves. Ecol Appl 13:S3-S7

Lucas MC, Baras E (2000) Methods for studying the spatial behaviour of freshwater fishes in the natural environment. Fish Fish 1:283-316

Meester GA, Mehrotra A, Ault JS, Baker EK (2004) Designing marine reserves for fishery management. Manag Sci 50(8): 1031-1043

Meyer CG, Holland KN, Wetherbee BM, Lowe CG (2000)

Editorial responsibility: Kenneth Sherman (Contributing

Editor), Narragansett, Rhode Island, USA
Movement patterns, habitat utilization, home range size and site fidelity of whitesaddle goatfish, Parupeneus porphyreus, in a marine reserve. Environ Biol Fish 59:235-242

O'Dor RK, Andrade Y, Webber DM, Sauer WHH, Roberts MJ, Smale MJ, Voegeli FM (1998) Applications and performance of radio-acoustic positioning and telemetry (RAPT) systems. Hydrobiologia 372:1-8

Palumbi SR, Gaines SD, Leslie H, Warner RR (2003) New wave: high-tech tools to help marine reserve research. Front Ecol Environ 1:73-79

Pauly D, Christensen V, Guenette S, Pitcher TJ, Sumaila UR, Walters CJ (2002) Towards sustainability in world fisheries. Nature 418:689-695

Roberts CM, Bohnsack JA, Gell F, Hawkins JP, Goodridge R (2001) Effects of marine reserves on adjacent fisheries. Science 294:1920-1923

Robichaud D, Rose GA (2002) Assessing evacuation rates and spawning abundance of marine fishes using coupled telemetric and acoustic surveys. ICES J Mar Sci 59:254-260

Robichaud D, Rose GA (2003) Sex differences in cod residency on a spawning ground. Fish Res 60:33-43

Schmidt KA (2004) Site fidelity in temporally correlated environments enhances population persistence. Ecol Lett 7: 176-184

Thorstad EB, Okland F, Rowsell D, McKinley RS (2000) A system for automatic recording of fish tagged with coded acoustic transmitters. Fish Manag Ecol 7:281-294

Tulevech SM, Recksiek CW (1994) Acoustic tracking of adult white grunt, Haemulon plumieri, in Puerto-Rico and Florida. Fish Res 19:301-319

Wetherbee BM, Holland KN, Meyer CG, Lowe CG (2004) Use of a marine reserve in Kaneohe Bay, Hawaii by the giant trevally, Caranx ignobilis. Fish Res 67:253-263

Zeller DC (1999) Ultrasonic telemetry: its application to coral reef fisheries research. Fish Bull US Natl Mar Fish Serv 97:1058-1065

Zeller DC, Russ GR (1998) Marine reserves: patterns of adult movement of the coral trout Plectropomus leopardus (Serranidae). Can J Fish Aquat Sci 55:917-924

Submitted: March 20, 2004; Accepted: November 8, 2004

Proofs received from author(s): March 30, 2005 